\title{
BMJ Open Success and limiting factors in health service innovation: a theory-generating mixed methods evaluation of UK projects
}

\author{
Kathleen Leedham-Green (D) , ${ }^{1}$ Alec Knight (D) , ${ }^{2}$ Gabriel B Reedy (D) ${ }^{3}$
}

To cite: Leedham-Green $\mathrm{K}$, Knight A, Reedy GB. Success and limiting factors in health service innovation: a theory-generating mixed methods evaluation of UK projects. BMJ Open 2021;11:e047943. doi:10.1136/ bmjopen-2020-047943

- Prepublication history and supplemental material for this paper is available online. To view these files, please visit the journal online (http://dx.doi. org/10.1136/bmjopen-2020047943).

Received 15 December 2020 Revised 30 March 2021 Accepted 09 April 2021

Check for updates

(c) Author(s) (or their employer(s)) 2021. Re-use permitted under CC BY-NC. No commercial re-use. See rights and permissions. Published by BMJ.

${ }^{1}$ Medical Education Research Unit, Faculty of Medicine, Imperial College London, London, UK

${ }^{2}$ School of Population Health and Environmental Sciences, Faculty of Life Sciences and Medicine, King's College London, London, UK

${ }^{3}$ Centre for Education, Faculty of Life Sciences and Medicine, King's College London, London, UK

Correspondence to Dr Kathleen Leedham-Green; k.leedham-green@imperial. ac.uk

\section{ABSTRACT}

Objectives To explore and explain success and limiting factors in UK health service innovation.

Design Mixed methods evaluation of a series of health service innovations involving a survey and interviews, with theory-generating analysis.

Setting The research explored innovations supported by one of the UK's Academic Health Science Networks which provides small grants, awards and structural support to health service innovators including clinical academics, health and social care professionals and third-sector organisations.

Participants All recipients of funding or support 20142018 were invited to participate. We analysed survey responses relating to 56 innovation projects.

Results Responses were used to conceptualise success along two axes: value creation for the intended beneficiaries and expansion beyond its original pilot. An analysis of variance between categories of success indicated that participation, motivation and evaluation were critical to value generation; organisational, educational and administrative support were critical to expansion; and leadership and collaborative expertise were critical to both value creation and expansion. Additional limiting factors derived from qualitative responses included difficulties navigating the boundaries and intersections between organisations, professions, sectors and cultures; a lack of support for innovation beyond the start-up phase; a lack of protected time; and staff burn-out and turnover.

Conclusions A nested hierarchy of innovation needs has been derived via an analysis of these factors, providing targeted suggestions to enhance the success of future innovations.

\section{BACKGROUND}

Healthcare systems worldwide are faced with increasing demand linked to the rising burden of disease within a resourceconstrained environment. ${ }^{1}$ This has led to a pressing need to find and disseminate innovative ways of meeting the healthcare needs of patients and communities in ways that are more sustainable. ${ }^{2}$ The WHO characterises health service innovation as 'a novel set of behaviours, routines, and ways of working
Strengths and limitations of this study

- A strength of this research is that it compares many innovations in a consistent way, and that it provides insights across a range of categories of success.

- A limitation of this research is that it is situated in a single geographical context; however, repeating these methods in different contexts should produce locally relevant results.

- Few mid-level theories relating to innovation are grounded in data that include projects that have not achieved their intended outcomes; therefore, we may have identified novel insights.

- Many of the success factors we have identified are not unique to this study; however, they have been subjected to further statistical analysis and found to differentiate significantly across categories of success in this context.

- More research is needed to examine whether addressing these factors prospectively enhances the success of future innovations.

that are discontinuous with previous practice, are directed at improving health outcomes, administrative efficiency, cost-effectiveness, or users' experience and that are implemented by planned and coordinated actions ${ }^{3}$ ( $p 7$ ).

Academic efforts in the health sciences continue to sharpen the focus on impact, rather than the creation of 'new knowledge' as the primary goal of research activity. At the vanguard are implementation scientists who work to translate research and innovation into clinical practice, navigating institutional, organisational, structural and cultural complexities to improve services. ${ }^{4}$ New support structures have emerged, such as the 15 Academic Health Science Networks set up in 2013 by the National Health Service (NHS) England, with funding streams that aim to support and encourage innovation at various levels. ${ }^{5}$ After more than half a decade of programme grants, the impact of these innovation programmes is a legitimate 
subject of enquiry: how and why have certain innovations become normalised, sustained or spread, and why have others struggled or stopped?

The knowledge created through an individual innovation is likely to be complex and context dependent, providing insights that may not necessarily be generalisable. ${ }^{6}$ Meta-analyses are faced with the complexity of synthesising multiple project evaluations that may be reported in different ways. The published literature on health service innovation contains few analyses of unsuccessful innovations, despite attempts to encourage negative reporting. ${ }^{7}$ By evaluating a large corpus of projects across one of these academic health sciences networks in a systematic way, we have an opportunity to directly compare innovations including those that may have struggled or stopped and not reached the literature.

This study thus sets out to explore a large number of innovations, both as individual projects in their unique local contexts, and as part of a larger integrative study. By isolating the factors that differentiate between categories of success, our aim is to produce an empirically derived explanatory model, and thereby to inform and enhance the success of future innovations.

\section{METHODS}

\section{Research aim}

To explore and explain success and limiting factors in health service innovation.

\section{Methodological orientation and theory}

This study is situated at the intersection of policy, social sciences and organisational research. Our philosophical assumptions are that there are real differences in the success of innovations, but also that success is fundamentally a subjective construct. Any research will only produce an approximation of the truth, and findings must be interpreted with an appreciation for context. We therefore position this research at the boundary of critical realism and constructivism. ${ }^{8}$

Adopting Varpio et al's terminology on the philosophy of research, we are taking an inductive approach that works towards a theoretical framework, rather than applying a pre-existing theoretical framework to this study.

We have adopted what Creswell et al refer to as a sequential mixed methods design. ${ }^{10}$ According to Creswell, insight can emerge from exploring first through qualitative methods (in our case a published qualitative review and interviews) the types of factors that might be important, and then designing questionnaires to explore their salience to a population (called an 'exploratory sequential design'). Insight can also emerge from collecting survey data initially and then following up with interviews to help explain the survey results in more detail: an 'explanatory sequential design'. Where both qualitative and quantitative data are collected simultaneously, one set of data can be used to triangulate the other (eg, where the meaning of one is unclear), or they can be used in complementary ways to illuminate each other (eg, one determining which factors are important, the other illuminating why that might be). Our research process involves both exploratory and explanatory aspects as well as triangulation and illumination. It is summarised in figure 1 .

\section{Context}

The Health Innovation Network (HIN) is one of the nationally funded Academic Health Science Networks set up by NHS England in 2013. It provides small grants, awards and structural support to academics, health and social care professionals and third-sector organisations, supporting service-level innovations to improve outcomes and value, including the sustainable use of resources. In addition, in the years 2014-2017, Health Education England (South London) provided investment in

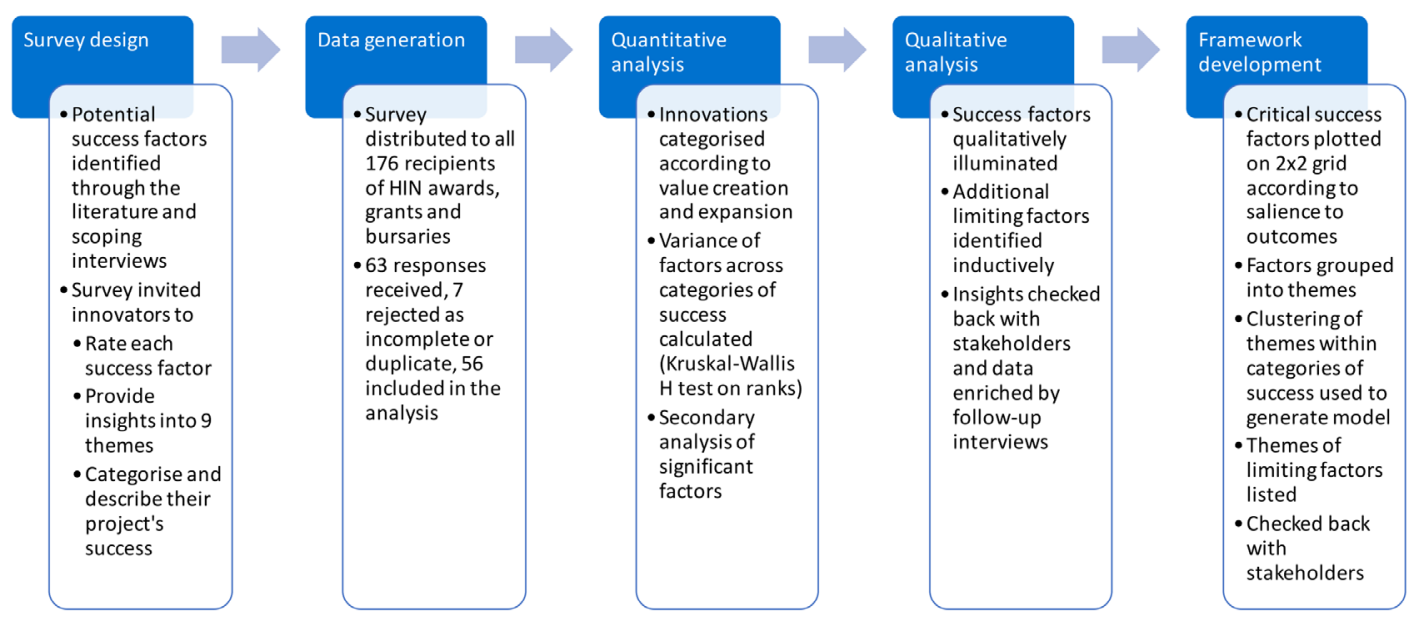

Figure 1 Research overview. A mixed methods sequential research process to explore and explain success factors and limiting factors in health service innovation. 
training and education innovation projects across healthcare settings in South London, through its strategic investment programme.

\section{Participants and sampling}

All recipients of HIN funding and Health Education England (South London) strategic investment programme funding and support during the years 20142018 were invited to participate. As our sample size was moderate, we aimed to analyse all responses and retrospectively determine whether the sample size was sufficient for thematic saturation and statistical inference. We achieved a priori thematic saturation for success factors (exemplar comments for each significant factor that we found) and inductive thematic saturation for limiting factors (content coded until no new themes arose). ${ }^{11}$

\section{Research team and ethics}

The research was commissioned by HIN in collaboration with Health Education England and conducted by an independent research team at King's College London. The research team comprised a postdoctoral educational psychologist/learning scientist (GBR), a postdoctoral occupational psychologist/health services researcher (AK) and a medical education research fellow (KLG). None were in a position of power or influence over participants, and the research was carefully designed to be conducted at arm's length from the funding agency. Survey responses were collected anonymously and decontextualised by the research team to encourage innovators to comment critically and safely about their projects. Innovation funding was not conditional on taking part in this research. Ethical approval was granted on 26 March 2019 by the Research Ethics Committee of King's College London (LRS-18/19-10432). Written informed consent was obtained from interviewees. Consent was implied from participation in the survey.

\section{Patient and public involvement}

No patient was involved. The primary stakeholders in this research were health service innovators who were involved in the survey design and in checking back and refining our interpretation.

\section{Data generation methods}

Survey design

The survey design began with the extraction of potential success factors for health service innovation from a recently published qualitative systematic review. ${ }^{12}$ This review aimed to identify all the factors and theories associated with sustainability and scale-up (capacity building) of innovations in health services research. KLG validated and expanded these factors through scoping interviews with five experienced health service innovators. The interviews started with an open exploration of what the innovator felt had impacted on the success of their project, followed by discussion on the factors identified through the literature. Personal factors were mentioned by all stakeholders in addition to the factors from the review, suggesting these may be under-reported. An additional theme (personal factors) with related subfactors was therefore included, based on these interviews. Themes and factors are listed in figure 2. These were used to create a mixed methods nested design survey ${ }^{13}$ using Qualtrics software (full text in online supplemental data).

The survey asked respondents to:

A. Categorise and describe their project's current status (no longer running/likely to finish soon/stable at the level of the original pilot/scaled up beyond the original pilot/too early to say/other).

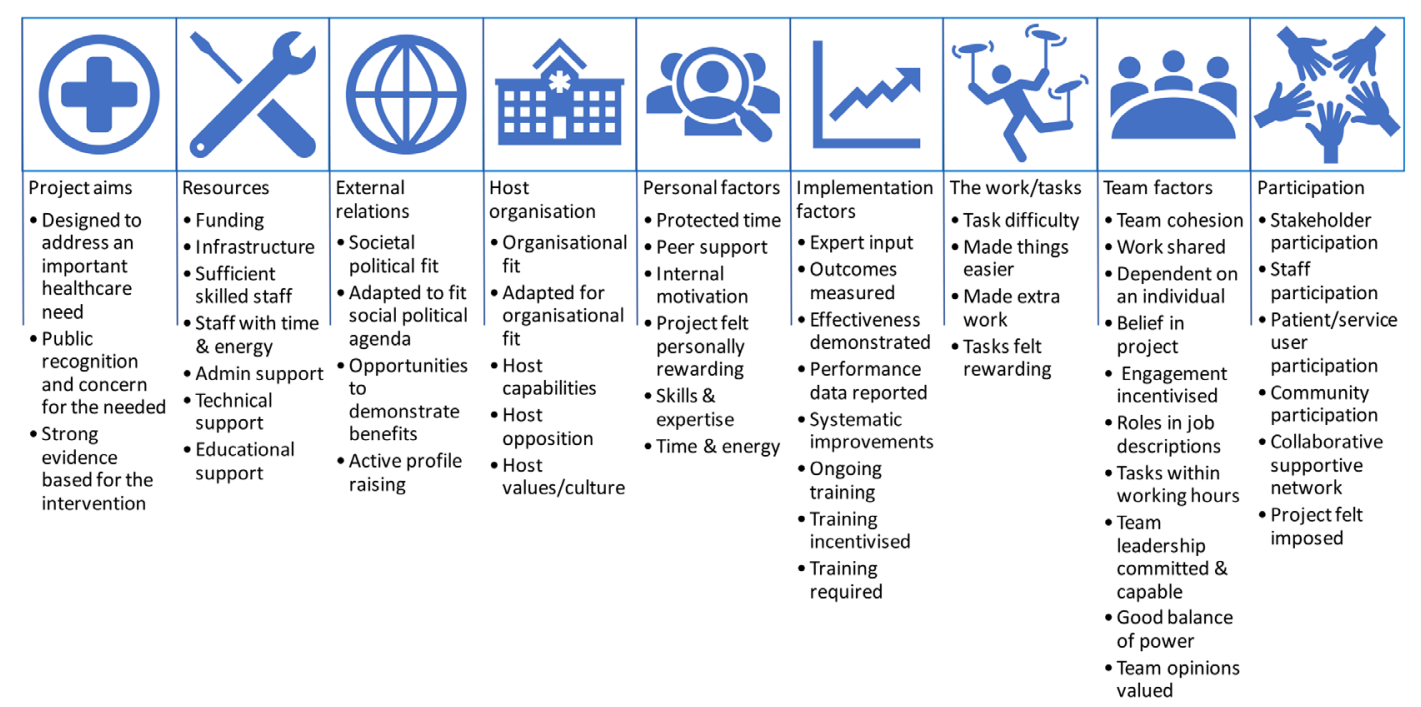

Figure 2 Survey scope. The survey scope was based on a qualitative review of theories and findings relating to the sustainability and scale-up of health service innovations ${ }^{12}$ supplemented by five scoping interviews. The questions are listed in table 1 , and the full-text survey is in the online supplemental material. 
B. Score statements (listed in table 1) relating to the impacts of each factor on their project's outcomes, grouped into nine themes on a 5-point disagree/ agree Likert scale.

C. Describe the status of their project and provide qualitative insights into each of the nine themes.

Our five stakeholders helped to improve the clarity, acceptability and usability of the survey questions and instructions.

\section{Survey distribution}

A neutral administrator from Health Education England distributed the survey by email in August and September 2019 to all 176 named recipients of HIN and Health Education England (South London) funding awards, grants and bursaries. A reminder was distributed 4 weeks later to participants who had not responded. Projects that had received more than one award were sent a single survey, and participants who had run more than one project were sent a separate survey for each project.

\section{Stakeholder follow-up interviews}

KLG checked back our results and interpretation with five stakeholders identified by HIN as experienced innovators, one of whom was also involved in the original scoping interviews. Interviews lasted 30-45 min and transcription was facilitated by automated software (otter. ai). These stakeholders helped to refine the model and confirmed its applicability and utility in their context. No new themes arose; however, quotes were used to enrich our survey data.

\section{Data analysis methods}

Development of categories of success

KLG and AK categorised projects into grades of success based on how the respondent self-categorised their project, triangulated against their qualitative survey responses. The categories of success were derived through an iterative process, involving both researchers agreeing a descriptive summary of the status of each project (eg, scaled down despite achieving better than expected patient outcomes; scaled down because the intervention did not achieve its aims). We grouped projects with similar project outcomes together, and through a process of constant comparison ${ }^{14}$ constructed a categorisation framework that accounted for all the cases in the set.

\section{Determination of salience of success factors}

We adopted an exploratory approach to data analysis, which aims to generate rather than test theory. ${ }^{15}$ KLG conducted an analysis of variance (ANOVA) for each of the scored factors (Kruskal-Wallis non-parametric ANOVA on rank using IBM SPSS V.25) to see whether there were significant differences between categories of success. The Kruskal-Wallis test does not assume a normal distribution in the data and can be used when the data are ordinal, for example, Likert scores. For asymmetric group sizes, the non-parametric Kruskal-Wallis test performs better than the parametric equivalent ANOVA method. ${ }^{16}$
For each factor that was identified as being significantly different between categories of success, we conducted a secondary analysis (box plot for each category) to confirm the direction and consistency of the association. This is generated automatically by SPSS after a KruskalWallis test. A graded 'exposure-response' relationship across all grades of success would be expected if a factor genuinely drives success. ${ }^{17}$ Where a graded relationship was not present, this is discussed in table 1.

\section{Illumination of success factors}

KLG and AK extracted quotes from the survey and interviews relating to each significant success factor to generate a rich description within each theme.

\section{Inductive analysis of limiting factors}

KLG coded the content of all qualitative data relating to challenges within projects that had not achieved their intended outcomes or that had scaled down or stopped $(\mathrm{n}=21)$ facilitated by NVivo V.12 software. GBR and KLG refined the codes and both authors worked together to inductively arrange the content into themes. ${ }^{18}$

\section{Development of final model}

We mapped significant factors onto a $2 \times 2$ grid using a natural logarithmic scatter plot so that factors that were significant to one dimension of success were mapped to the right half of the grid, factors that were significant to a second dimension of success were mapped to the top half and factors that were significant to both were mapped to the top right quadrant. We grouped success factors into themes through a process of collaborative discussion, and we explored which themes predominated in each quadrant to generate our model which was checked back with stakeholders.

\section{RESULTS}

\section{Descriptive summary}

We received 63 responses, but seven were incomplete or duplicate so a total of 56 responses (31.8\% of 176) were included in the analysis. Each response related to a different innovation project. Survey respondents selfidentified within one or more of the following groups: the project leadership team $(\mathrm{n}=54)$; service delivery team $(\mathrm{n}=9)$; training team $(\mathrm{n}=9)$; administrative team $(\mathrm{n}=6)$; service lead $(n=2)$; and patient/service user $(n=1)$. Several respondents identified within multiple groups.

Projects were situated in secondary care $(n=19)$; community care $(n=14)$; academic sector $(n=5)$; mental health sector $(n=4)$; online $(n=4)$; primary care $(n=3)$; and the hospice sector $(n=2)$, with the remainder working at the interfaces between services, or across sectors. Their scope ranged from national programmes at hundreds of sites, local programmes supporting tens of thousands of patients, to small intensive innovations working in new ways with a few dozen complex patients, and their duration ranged from 1 to 5 years. The innovation areas 
Table 1 Analysis of variance of potential success factors across categories of success

\begin{tabular}{|c|c|c|c|c|c|c|}
\hline & \multirow[b]{2}{*}{ Factor } & \multirow{2}{*}{$\begin{array}{l}\text { Average answer } \\
\text { across all } \\
\text { categories }^{*}\end{array}$} & \multirow[t]{2}{*}{$\begin{array}{l}\text { Distribution of } \\
\text { factor is the same } \\
\text { across categories } \\
\text { of expansion } \\
\text { (proven value) } \\
\text { Significance } †\end{array}$} & \multirow[t]{2}{*}{$\begin{array}{l}\text { Distribution of } \\
\text { factor is the } \\
\text { same across } \\
\text { categories of } \\
\text { expansion (all) } \\
\text { Significance }\end{array}$} & \multirow[t]{2}{*}{$\begin{array}{l}\text { Distribution of } \\
\text { factor is the } \\
\text { same across } \\
\text { categories of } \\
\text { realised value } \\
\text { Significance } \\
\end{array}$} & \multirow{2}{*}{$\begin{array}{l}\text { Interpretation and } \\
\text { comment on secondary } \\
\text { analysis } ¥\end{array}$} \\
\hline & & & & & & \\
\hline 1 & $\begin{array}{l}\text { The initiative was } \\
\text { designed to end } \\
\text { once a set outcome } \\
\text { had been achieved. }\end{array}$ & -0.40 & 0.274 & 0.172 & 0.317 & \\
\hline 2 & $\begin{array}{l}\text { The initiative was } \\
\text { designed to end after } \\
\text { defined period of } \\
\text { time. }\end{array}$ & -0.58 & 0.011 & 0.011 & 0.288 & $\begin{array}{l}\text { Unsurprisingly, even projects } \\
\text { with high-realised value } \\
\text { finish if they are time bound. }\end{array}$ \\
\hline 3 & $\begin{array}{l}\text { The initiative was } \\
\text { designed to address } \\
\text { an important } \\
\text { healthcare need. }\end{array}$ & $\uparrow 1.63$ & 0.765 & 0.712 & 0.135 & \\
\hline 4 & $\begin{array}{l}\text { There was public/ } \\
\text { political recognition } \\
\text { and concern for } \\
\text { the problem that } \\
\text { the initiative was } \\
\text { designed to address. }\end{array}$ & $\uparrow 1.23$ & 0.939 & 0.66 & 0.201 & \\
\hline 5 & $\begin{array}{l}\text { The initiative was } \\
\text { based on a strong } \\
\text { evidence base, and it } \\
\text { was credible that the } \\
\text { stated benefits could } \\
\text { be achieved through } \\
\text { the project plan. }\end{array}$ & $\uparrow 1.35$ & 0.696 & 0.355 & 0.299 & \\
\hline 8 & $\begin{array}{l}\text { There were sufficient } \\
\text { members of staff } \\
\text { with the right } \\
\text { skills to meet the } \\
\text { requirements of the } \\
\text { initiative. }\end{array}$ & $\uparrow 1.42$ & 0.003 & 0.002 & 0.013 & $\begin{array}{l}\text { Skilled workforce is a critical } \\
\text { success factor across all } \\
\text { definitions of success. }\end{array}$ \\
\hline 9 & $\begin{array}{l}\text { Members of staff had } \\
\text { sufficient energy and } \\
\text { time to dedicate to } \\
\text { the initiative. }\end{array}$ & $\uparrow 1.21$ & 0.033 & 0.085 & 0.362 & $\begin{array}{l}\text { Time and energy are } \\
\text { critical to whether proven } \\
\text { innovations expand. }\end{array}$ \\
\hline 10 & $\begin{array}{l}\text { There was sufficient } \\
\text { administrative } \\
\text { support to deliver } \\
\text { and maintain the } \\
\text { initiative. }\end{array}$ & 0.85 & 0.013 & 0.019 & 0.142 & $\begin{array}{l}\text { Administrative support } \\
\text { is critical to whether an } \\
\text { innovation expands. }\end{array}$ \\
\hline 11 & $\begin{array}{l}\text { There was sufficient } \\
\text { technical support to } \\
\text { deliver and maintain } \\
\text { the initiative. }\end{array}$ & 1.04 & 0.113 & 0.187 & 0.657 & \\
\hline
\end{tabular}


Table 1 Continued

\begin{tabular}{|c|c|c|c|c|c|}
\hline \multirow[b]{2}{*}{ Factor } & \multirow{2}{*}{$\begin{array}{l}\text { Average answer } \\
\text { across all } \\
\text { categories* }^{*}\end{array}$} & $\begin{array}{l}\text { Distribution of } \\
\text { factor is the same } \\
\text { across categories } \\
\text { of expansion } \\
\text { (proven value) } \\
\end{array}$ & $\begin{array}{l}\text { Distribution of } \\
\text { factor is the } \\
\text { same across } \\
\text { categories of } \\
\text { expansion (all) } \\
\end{array}$ & $\begin{array}{l}\text { Distribution of } \\
\text { factor is the } \\
\text { same across } \\
\text { categories of } \\
\text { realised value } \\
\end{array}$ & \multirow{2}{*}{$\begin{array}{l}\text { Interpretation and } \\
\text { comment on secondary } \\
\text { analysis } ¥\end{array}$} \\
\hline & & Significance† & Significance† & Significance† & \\
\hline $\begin{array}{l}\text { There was sufficient } \\
\text { educational } \\
\text { support to deliver } \\
\text { and maintain the } \\
\text { initiative. }\end{array}$ & $\uparrow 1.30$ & 0.023 & 0.012 & 0.089 & $\begin{array}{l}\text { Educational support is } \\
\text { critical to whether an } \\
\text { innovation expands. }\end{array}$ \\
\hline $\begin{array}{l}\text { External political } \\
\text { or societal factors } \\
\text { impacted negatively } \\
\text { on the delivery of the } \\
\text { initiative. }\end{array}$ & -0.91 & 0.191 & 0.141 & 0.005 & $\begin{array}{l}\text { External political or societal } \\
\text { factors appear critical to } \\
\text { whether an innovation is } \\
\text { able to realise its intended } \\
\text { value (inconsistent exposure/ } \\
\text { response). }\end{array}$ \\
\hline $\begin{array}{l}\text { We had opportunities } \\
\text { to demonstrate } \\
\text { the benefits of this } \\
\text { innovation within } \\
\text { our organisation } \\
\text { and/or to other } \\
\text { organisations. }\end{array}$ & $\uparrow 1.59$ & 0.237 & 0.053 & 0.02 & $\begin{array}{l}\text { Unsurprisingly, innovations } \\
\text { that were able to realise } \\
\text { their intended value were } \\
\text { more likely to be able to } \\
\text { demonstrate the benefits of } \\
\text { their innovation. }\end{array}$ \\
\hline $\begin{array}{l}\text { There are plans } \\
\text { to replicate this } \\
\text { innovation at other } \\
\text { sites or spread it to } \\
\text { other parts of the } \\
\text { organisation. }\end{array}$ & 0.58 & 0.024 & 0.012 & 0.228 & $\begin{array}{l}\text { Unsurprisingly, innovations } \\
\text { that have become scaled up } \\
\text { were more likely to say there } \\
\text { were plans to spread their } \\
\text { innovation. }\end{array}$ \\
\hline $\begin{array}{l}\text { The initiative } \\
\text { integrated well } \\
\text { into existing } \\
\text { organisational } \\
\text { structures, } \\
\text { programmes or } \\
\text { policies. }\end{array}$ & $\uparrow 1.26$ & 0.012 & 0.002 & 0.059 & $\begin{array}{l}\text { The ability of an innovation } \\
\text { to integrate into existing } \\
\text { organisational structures } \\
\text { may be critical to whether it } \\
\text { becomes scaled up. }\end{array}$ \\
\hline $\begin{array}{l}\text { It was necessary to } \\
\text { adapt the initiative } \\
\text { so that it achieved a } \\
\text { good fit with existing } \\
\text { organisational } \\
\text { structures, } \\
\text { programmes or } \\
\text { policies. }\end{array}$ & $\rightarrow-0.09$ & 0.053 & 0.035 & 0.115 & $\begin{array}{l}\text { For innovations to scale up, } \\
\text { they may need to adapt so } \\
\text { that they fit within existing } \\
\text { organisational structures. }\end{array}$ \\
\hline
\end{tabular}




\begin{tabular}{|c|c|c|c|c|c|}
\hline \multirow[b]{2}{*}{ Factor } & \multirow{2}{*}{$\begin{array}{l}\text { Average answer } \\
\text { across all } \\
\text { categories* }\end{array}$} & \multirow[t]{2}{*}{$\begin{array}{l}\text { Distribution of } \\
\text { factor is the same } \\
\text { across categories } \\
\text { of expansion } \\
\text { (proven value) } \\
\text { Significancet }\end{array}$} & \multirow[t]{2}{*}{$\begin{array}{l}\text { Distribution of } \\
\text { factor is the } \\
\text { same across } \\
\text { categories of } \\
\text { expansion (all) } \\
\text { Significance }\end{array}$} & \multirow[t]{2}{*}{$\begin{array}{l}\text { Distribution of } \\
\text { factor is the } \\
\text { same across } \\
\text { categories of } \\
\text { realised value } \\
\text { Significance }\end{array}$} & \multirow{2}{*}{$\begin{array}{l}\text { Interpretation and } \\
\text { comment on secondary } \\
\text { analysis } ¥\end{array}$} \\
\hline & & & & & \\
\hline $\begin{array}{l}\text { The host } \\
\text { organisation was } \\
\text { ready and able } \\
\text { to undertake the } \\
\text { initiative. }\end{array}$ & $\uparrow 1.55$ & 0.262 & 0.168 & 0.721 & \\
\hline $\begin{array}{l}\text { The initiative was } \\
\text { hampered by } \\
\text { opposition from } \\
\text { within the host } \\
\text { organisation. }\end{array}$ & $\downarrow-1.50$ & 0.037 & 0.027 & 0.398 & $\begin{array}{l}\text { However valuable an } \\
\text { innovation is, it appears } \\
\text { unlikely to survive if it is } \\
\text { opposed within the host } \\
\text { organisation. }\end{array}$ \\
\hline $\begin{array}{l}\text { I was released from } \\
\text { other duties so that I } \\
\text { could implement this } \\
\text { initiative. }\end{array}$ & -0.43 & 0.732 & 0.893 & 0.789 & \\
\hline $\begin{array}{l}\text { I had a supportive } \\
\text { peer network that I } \\
\text { could discuss any } \\
\text { issues or problems } \\
\text { with. }\end{array}$ & $\uparrow 1.32$ & 0.385 & 0.562 & 0.79 & \\
\hline $\begin{array}{l}\text { I feel I had the right } \\
\text { skills/experience/ } \\
\text { training to implement } \\
\text { and sustain the } \\
\text { initiative. }\end{array}$ & $\uparrow 1.62$ & 0.033 & 0.008 & 0.023 & $\begin{array}{l}\text { The skills of the innovator } \\
\text { appear to be a critical } \\
\text { success factor across all } \\
\text { definitions of success. }\end{array}$ \\
\hline $\begin{array}{l}\text { I had sufficient } \\
\text { energy and time } \\
\text { to dedicate to the } \\
\text { initiative. }\end{array}$ & 1.06 & 0.209 & 0.268 & 0.498 & \\
\hline $\begin{array}{l}\text { The project had } \\
\text { sufficient input } \\
\text { from experts with } \\
\text { the necessary } \\
\text { knowledge and } \\
\text { experience. }\end{array}$ & $\uparrow 1.66$ & 0.134 & 0.018 & 0.021 & $\begin{array}{l}\text { Expert input appears critical } \\
\text { to both realisation of value, } \\
\text { and to whether it expands. }\end{array}$ \\
\hline $\begin{array}{l}\text { The outcomes and } \\
\text { impact of the project } \\
\text { were measured or } \\
\text { assessed. }\end{array}$ & $\uparrow 1.37$ & 0.060 & 0.125 & 0.119 & \\
\hline
\end{tabular}


Table 1 Continued

32 Performance data

1.04

0.346

Distribution of

Distribution of

factor is the

across categories

same across

of expansion

categories of

(proven value)

expansion (all)

Distribution of

factor is the

Average answer

Factor

categories*

Significance $†$

Significance $\dagger$

ategories

$31 \quad$ We were able to

0.463

0.185

realised value

effectiveness of the

project.

\section{were gathered and}

reported on a regular basis.

Steps were taken

to systematically

improve and adapt

the project.

$34 \quad$ There was ongoing

orientation and

training available, for

example, to new staff

or to build capacity.

35 Staff were given

time/incentives to

attend the necessary

training.

36 Staff were required

to attend the necessary training

37 The initiative was difficult or complex to deliver.

38 The initiative helped

to make things easier

0.153

0.377

0.87

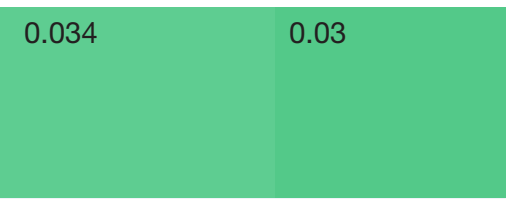

0.153

Significance†

Interpretation and comment on secondary analysisł

Unsurprisingly, innovations

that were able to realise

their intended value

were more likely to be

able to demonstrate the

effectiveness of their innovation.

0.159

$\begin{array}{lll}0.096 & 0.159 & 0.178\end{array}$

0.11

0.348

0.271

0.767

$-0.09$

0.294

0.163

0.158

0.76

0.86

0.953

0.182

or more efficient.

$39 \quad$ The initiative did not $\downarrow-1.09$

require special or

extra effort.

40 I believe that the

staff delivering the initiative found the work/tasks rewarding and satisfying.

worked well together.

42 There were clear

responsibilities for individuals the work was shared across the team.

43 Project was overly dependent on a particular individual or individuals.

$\begin{array}{llll}\uparrow .74 & 0.416 & 0.796 & 0.893 \\ & 0.945 & 0.533 & 0.066 \\ 0.57 & 0.708 & 0.355 & 0.29 \\ & & \\ & & \end{array}$

The availability of ongoing training may be critical to whether successful innovations scale up. 


\begin{tabular}{|c|c|c|c|c|c|c|}
\hline & \multirow[b]{2}{*}{ Factor } & \multirow{2}{*}{$\begin{array}{l}\text { Average answer } \\
\text { across all } \\
\text { categories* }^{\star}\end{array}$} & \multirow[t]{2}{*}{$\begin{array}{l}\text { Distribution of } \\
\text { factor is the same } \\
\text { across categories } \\
\text { of expansion } \\
\text { (proven value) } \\
\text { Significancet }\end{array}$} & \multirow[t]{2}{*}{$\begin{array}{l}\text { Distribution of } \\
\text { factor is the } \\
\text { same across } \\
\text { categories of } \\
\text { expansion (all) } \\
\text { Significance }\end{array}$} & \multirow[t]{2}{*}{$\begin{array}{l}\text { Distribution of } \\
\text { factor is the } \\
\text { same across } \\
\text { categories of } \\
\text { realised value } \\
\text { Significance }\end{array}$} & \multirow{2}{*}{$\begin{array}{l}\text { Interpretation and } \\
\text { comment on secondary } \\
\text { analysis } ¥\end{array}$} \\
\hline & & & & & & \\
\hline 44 & $\begin{array}{l}\text { I believe that the } \\
\text { team understood } \\
\text { what the project was } \\
\text { trying to achieve and } \\
\text { that it would lead to } \\
\text { improved processes } \\
\text { and outcomes. }\end{array}$ & $\uparrow 1.62$ & 0.218 & 0.165 & 0.772 & \\
\hline 45 & $\begin{array}{l}\text { There were rewards } \\
\text { or incentives } \\
\text { that supported } \\
\text { engagement with, } \\
\text { and continued } \\
\text { delivery of, the } \\
\text { initiative. }\end{array}$ & 0.07 & 0.45 & 0.638 & 0.228 & \\
\hline 46 & $\begin{array}{l}\text { The activities and } \\
\text { roles of the initiative } \\
\text { were incorporated } \\
\text { into job descriptions. }\end{array}$ & -0.30 & 0.29 & 0.243 & 0.141 & \\
\hline 47 & $\begin{array}{l}\text { Staff had time within } \\
\text { their working hours } \\
\text { to complete the } \\
\text { tasks of the initiative. }\end{array}$ & 0.59 & 0.251 & 0.138 & 0.328 & \\
\hline 48 & $\begin{array}{l}\text { The initiative had } \\
\text { leadership and/ } \\
\text { or champions who } \\
\text { were committed and } \\
\text { capable. }\end{array}$ & $\uparrow 1.62$ & 0.003 & 0.001 & 0.006 & $\begin{array}{l}\text { Leadership appears to be } \\
\text { a highly significant success } \\
\text { factor across all definitions } \\
\text { of success. }\end{array}$ \\
\hline 50 & $\begin{array}{l}\text { Team members } \\
\text { were able to express } \\
\text { their opinions, and } \\
\text { their opinions were } \\
\text { valued. }\end{array}$ & $\uparrow 1.91$ & 1 (no variance) & 0.049 & 0.026 & $\begin{array}{l}\text { Distributed decision-making } \\
\text { may be a critical success } \\
\text { factor across all definitions } \\
\text { of success. It was common } \\
\text { to all innovations of value } \\
\text { that scaled up (hence no } \\
\text { variance). }\end{array}$ \\
\hline 51 & $\begin{array}{l}\text { There was a sense } \\
\text { of ownership and } \\
\text { commitment by } \\
\text { those involved with } \\
\text { the initiative }\end{array}$ & $\uparrow 1.79$ & 0.284 & 0.177 & 0.102 & \\
\hline 52 & $\begin{array}{l}\text { Staff who were } \\
\text { responsible for } \\
\text { delivering the } \\
\text { initiative were } \\
\text { involved as partners, } \\
\text { and were able to } \\
\text { shape the initiative. }\end{array}$ & $\uparrow 1.74$ & 0.306 & 0.176 & 0.031 & $\begin{array}{l}\text { Participatory processes with } \\
\text { staff may be critical to the } \\
\text { ability of a project to realise } \\
\text { its intended value. }\end{array}$ \\
\hline
\end{tabular}




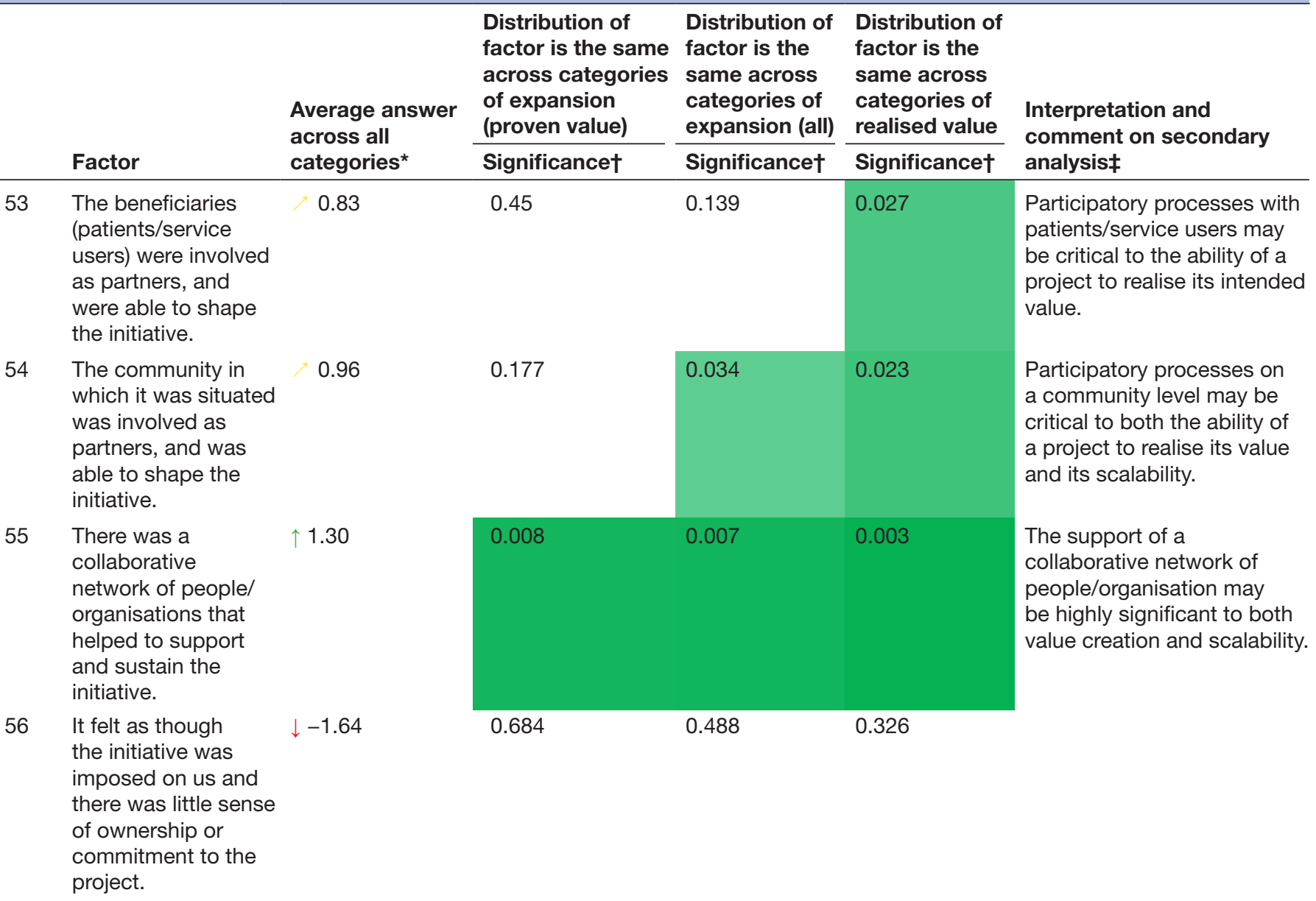

Analysis of variance of potential success factors across categories of success.

${ }^{*}$ Respondents on average $\uparrow=$ agree, =somewhat agree, $\quad$ =neither agree nor disagree, =somewhat disagree, $\downarrow=$ disagree. †Asymptotic significances are displayed. The significance level is 0.05 . The darker the shading, the safer it is to reject the null hypothesis. Significance $<0.05$ indicates $>95 \%$ certainty that the difference between categories is not random. $\ddagger$ Secondary analysis examined the direction of the association and the strength of effect across categories of success.

related to new ways of working in end-of-life care; disability enablement; support for complex or vulnerable patients; discharge support; pain management; patient safety innovations; recovery and rehabilitation; personalised care; chronic conditions; new models of integrated health and social care; health promotion; and novel simulation and workforce development strategies. Typical projects can be explored at the HIN website ${ }^{19}$; however, for reasons of confidentiality, we cannot specify which were included in this study.

\section{Categories of success}

Our emergent framework categorised each project's success across two dimensions: the first relating to whether the innovation was reported as generating more or less than its anticipated value for patients/carers ('value creation axis'), the second according to whether the project became sustained or scaled up beyond the initial pilot, or whether it was scaled down or stopped ('expansion axis'). Innovations that were within the scope and intentions of the original pilot were positioned centrally.
We initially scored projects into five categorisations across the expansion axis, as some projects expanded locally and some nationally; however, there were not enough projects in each group and statistics became unreliable, so we made a pragmatic decision to adopt relative rather than absolute categories.

The resulting categorical framework is illustrated in figure 3 , with the number of innovations in each category shown in brackets.

\section{Success factors}

Our analysis compared the variance of success factors across innovations that had demonstrated lower than expected value $(n=11)$, value as expected $(n=25)$ and higher than expected value $(n=20)$. Next, we compared variance across innovations that had diminished in scope or stopped $(n=17)$, innovations that were running as expected $(\mathrm{n}=16)$ and innovations that had scaled up $(\mathrm{n}=23)$. Finally, we excluded low-value projects and analysed again across the expansion axis $(n=10, n=12$ and 


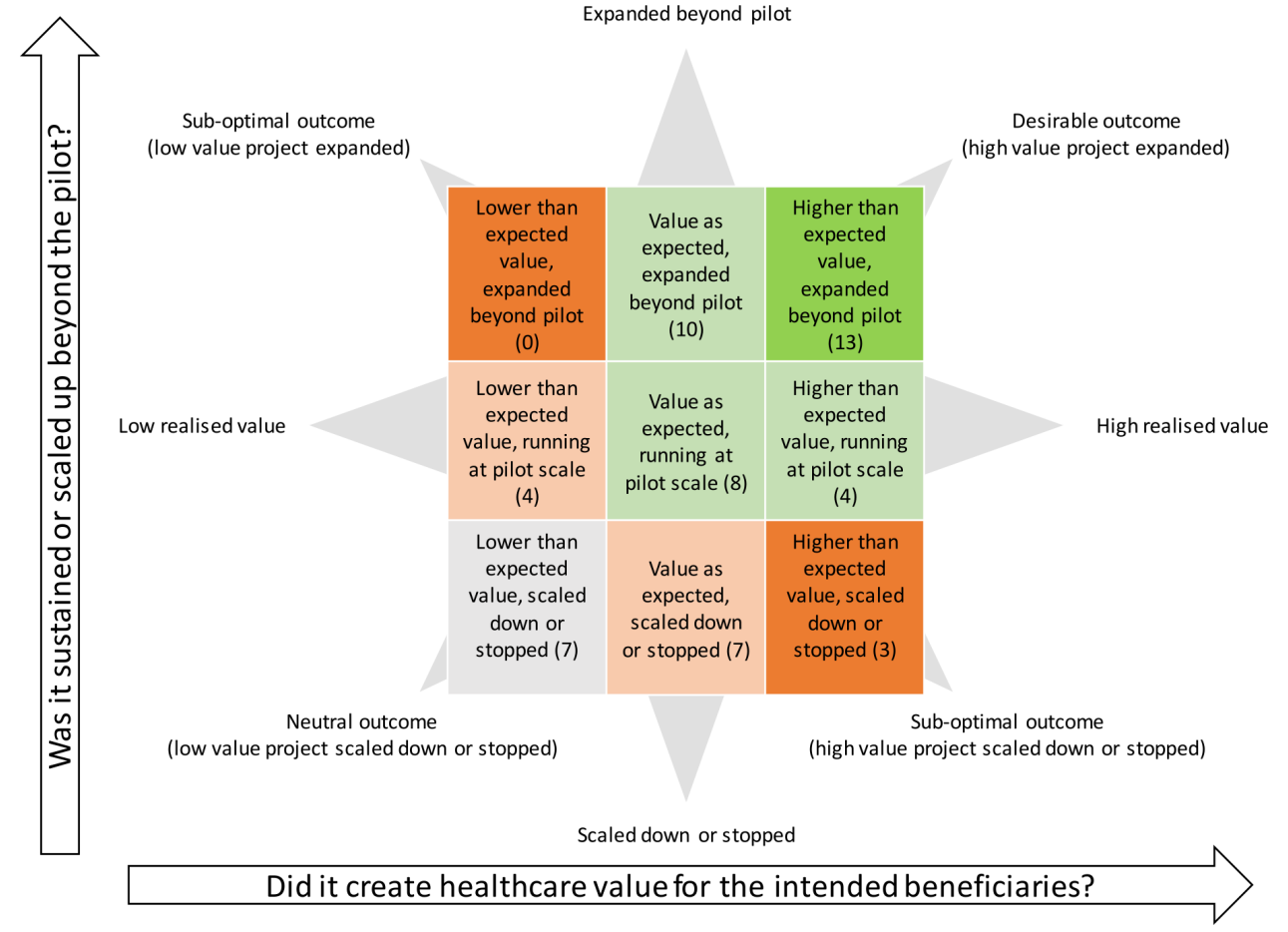

Figure 3 Framework for categorisation of success within health service innovation Health service innovations were categorised across two dimensions of success through an inductive classification process. The horizontal axis relates to how successful innovations were in realising their intended value: 'did it create more or less than its intended value for beneficiaries?' The vertical axis relates to expansion: 'was the innovation scaled up or scaled down from the original pilot?' Numbers in brackets indicate how many innovations were found in each category.

$\mathrm{n}=23$, respectively), seeking to explore why innovations with proven value had not been scaled up.

Our analysis is presented in table 1 with significant results $(\mathrm{p}<0.05)$ shaded in green. At this level of significance, there is a 1 in 20 probability that a result is in fact random. We have used lighter shading to indicate factors that might potentially be significant, or which could be found not to be significant if the power of the study was increased. The final column gives our interpretation of the more significant findings $(\mathrm{p}<0.05)$ that takes into consideration our secondary analysis.

Many factors were similarly scored across all categories of success, for example, information technology (IT) infrastructure. This does not mean that these factors are not important, only that they were experienced similarly across all categories of success and are therefore unlikely to be the underlying cause of the relative success or failure of a project.

We have collated the significant factors together in table 2 with illuminative quotes, and we discuss both positive and negative findings within each of the nine survey themes below.

\section{Project-related factors}

Interestingly, the aims of the project did not appear to be critical to success. Both successful and unsuccessful innovations were similarly reported as being designed to address an important healthcare need that was concerning to the public. All funded projects were required to articulate a credible evidence base arguing that stated benefits could be achieved through the project plan.

\section{Resourcing and expertise}

All significant resource-related success factors were associated with the workforce. Non-critical factors included infrastructure (such as buildings, materials and supplies), which were reported as sufficient; IT, which was moderately good across all categories of success; and funding issues, which were also similar across all categories of success. However, having the right numbers of staff with the right skills appeared to be highly significant, both in terms of the project being able to realise its intended value, as well as for it to become scaled up beyond the original pilot. Staff with time and energy appeared critical to whether successful innovations became scaled up, as were administrative and educational support, including the availability of ongoing educational support (eg, orientation and training for new staff, or to build capacity). Expertise appeared to be critical across all categories of success, both in terms of the innovator feeling they had the right skills, experience or training; the project having access to staff with the right skills; and having external expert input where needed.

\section{External factors}

Alignment to societal needs appeared to correlate with whether a project was able to realise its intended value, but less so with its expansion. However, as the effect size did 
Table 2 Factors that are significantly associated with innovation success with illustrative quotes

\section{Significant factors by theme (significant to value or expansion)}

Theme 1: Project aims

\section{Theme 2: Resources and support}

- There were sufficient members of staff with the right skills to meet the requirements of the initiative (significant to expansion and value).

- Members of staff had sufficient energy and time to dedicate to the initiative (expansion).

- There was sufficient administrative support to deliver and maintain the initiative (expansion).

- There was sufficient educational support to deliver and maintain the initiative (expansion).

\section{Illustrative quotes}

None of the factors related to the aims of the project were significant.

'The programme support sat with one individual rather than a team and as highlighted previously the administrative/programme support hadn't been entirely appreciated/factored in at the outset of the programme.' (R16)

'There are innovators out there who are doing things on their own, and the person I'm thinking about is not in a very good place. He's got virtually no support, and I don't know how he does it.' (FI2)

'The resources needed in terms of administration and support were underestimated. We input far more time and admin resources than originally planned.' (R15)

'The envelope of funding available did not enable us to fully develop a training package which was what we had initially hoped to do.' (R25)

Theme 3: How the project interfaced externally

- External political or societal factors impacted negatively on the delivery of the initiative (value, scored negatively).

- We had opportunities to demonstrate the benefits of this innovation within our organisation and/or to other organisations (value).

'The project piggy-backed on the current social movement highlighting the needs of mental health.' (R18)

'Hearing has always been the poor relation to other health issues even though everyone knows someone struggles with their hearing either family or friends.' (R35)

Theme 4: Organisational factors

'The project was presented in [area] Council, [area] NHS Trust, to the

- The initiative integrated well into existing organisational structures, public health team in the council and the voluntary sector in [area]. It programmes or policies (expansion).

- The initiative was hampered by opposition from within the host organisation (expansion). being drafted.' (R13)

'There was also a disconnect between commissioner priorities \& [the host organisation's] priorities in relation to the programme, which impacted on its sustainability \& roll-out.' (R16)

Theme 5: Personal factors

- I was internally motivated to implement this initiative (value).

- I found working on the initiative personally rewarding (value).

- I feel I had the right skills/experience/training to implement and sustain the initiative (expansion and value).

'I was very motivated to implement this project which was demanding as I had no protected time for it. Nonetheless, you do what is needed to achieve a goal.' (R18)

'I am very proud of our achievements and that the work has become a routine part of our culture and system of working.' (R28)

'On reflection I needed to lead this project more strongly. I tried to be facilitative and not prescriptive, but the staff were not experienced enough to utilise this opportunity. They needed more direction and support. There was some conflict between the educators and the substantive staff.' (R10)

Theme 6: Project management

- The project had sufficient input from experts with the necessary 'As the project was run within [university] and [tertiary hospital trust], knowledge and experience (value).

- We were able to demonstrate the effectiveness of the project (value).

'The ongoing reporting allowed for the results to be understood early in the project, shared and used in the strategy for delivering education across [region].' (R5)

'A robust evaluation was undertaken of the programme, along with regular review points to inform adaptations/opportunities for improvement.' (R16) 
Table 2 Continued

Significant factors by theme (significant to value or expansion)

Theme 8: Team processes

- There was ongoing orientation and training available, for example, to new staff or to build capacity (expansion).

- The initiative had leadership and/or champions who were committed and capable (expansion and value).

- Team members were able to express their opinions, and their opinions were valued (expansion and value).

\section{Illustrative quotes}

'We always express the value of our service users, administrator, and other members of the team and meet regularly to discuss well-being, progress, and evaluation.' (R33)

'The team got on. It was a lovely team and dynamics. We all believed in the idea and were excited about it. Obviously the project needs expertise in [technology], so in that regard the work was dependent on the availability of such expertise within the team.'

'Leadership hasn't been invested in providing the platform for the workshops \& curriculum to be rolled out. Lip service given by leadership.' (R56)

'This programme was carried out by a team but lead by myself. Other parties lacked the time and incentive to commit to running and leading the programme after the 12 months of my time being project lead.' (R46)

\footnotetext{
Theme 9: Collaborative and participatory practices

- Staff who were responsible for delivering the initiative were involved as partners, and were able to shape the initiative (value).

- The beneficiaries (patients/service users) were involved as partners, and were able to shape the initiative (value).

- The community in which it was situated was involved as partners, and was able to shape the initiative (value).

- There was a collaborative network of people/organisations that helped to support and sustain the initiative (expansion and value).
}

'We've had some sort of service user involvement all the way through... that's really improved the way we've reflected and talked... it gives a genuineness to what we're trying to achieve... the fact that you go and work with the associates and carers, you actually go and look at the environment, you spend time with the nurses that you're going to be teaching and all the other people that you're working with, really helps to, you know, it definitely adds value to the project.' (FI3)

'There was a single practitioner using the resource on her own, and now it is nationally recognised... Without that level of support: the time, the people and the resources, we wouldn't have got anywhere. It's been a fantastic level of support. They designed an implementation toolkit to support practitioners embedding the programme locally.' (FI2)

'The team at the [innovation network] were fabulous and so supportive.' (R12)

The nine themes and factors were derived from a qualitative review of the literature supplemented by stakeholder interviews. Significant factors were derived through a survey that explored salience of factors to outcomes. Survey respondents are indicated by R(n) and follow-up interview respondents by $\mathrm{FI}(\mathrm{n})$.

not grow consistently across categories of value creation, we cannot necessarily infer a causal relationship. ${ }^{17}$ Qualitative comments indicated that projects that were able to align themselves to current political or societal agendas, such as mental health, were more successful. Conversely, those attempting to work in relatively less topical areas of practice described difficulty securing strategic funding, so we have tentatively included this factor in our model.

\section{Organisational factors}

Our analysis of organisational factors indicated that the ability of an innovation to integrate into existing organisational structures, programmes or policies may be critical to whether it scales up, and possibly also to its ability to create value $(\mathrm{p}=0.059)$. Successful projects described adapting where necessary to achieve a good fit within organisational priorities. For the most part, host organisations were described as having a positive learning culture and were ready and able to undertake innovative initiatives; however, even innovations with proven value were unable to survive if there was opposition within the host organisation.

\section{Personal factors}

Few respondents reported being released from other duties so that they could implement their initiative. However, most respondents said they benefited from a supportive peer culture. Respondents who were able to realise value were significantly more like to say they were internally motivated and found working on the project rewarding.

\section{Project management}

Most projects measured or assessed the outcomes and impacts of the project, though this appeared to be more common in successful projects $(p=0.060)$. Projects with high value were able to demonstrate and share this success. Leadership appeared to be a highly significant 
success factor across all categories of success, with struggling or unsuccessful projects citing leadership failures.

\section{The tasks of the project}

Similar to theme 2, which explored the aims of the project, the tasks of the project did not appear to be significantly different across categories of success.

\section{Collaborative and participatory practices}

Valuing team members' opinions was highly significant across all categories of success and was present in all projects that were scaled up (hence variance not calculable). Participatory approaches were significantly associated with the ability of an innovation to generate value. These participatory processes related to the staff delivering the innovation, the intended beneficiaries and the communities in which the innovations were situated.

Finally, one of the most significant differentiating factors across all categories of success was engagement with a collaborative network that helped to support and sustain the initiative.

\section{Limiting factor analysis}

In addition to the above success factors, which were quantitatively identified, the following limiting factors were identified through our qualitative analysis of failed or struggling projects. As our limiting factor analysis is qualitative and interpretive, we present our data in line with our analysis.

\section{Boundaries between commercial, voluntary and public sectors}

While UK healthcare is primarily publicly funded and provided by the NHS, social care is often commercially provided, ${ }^{20}$ creating the potential for friction at the interfaces between these sectors.

As the care homes are private businesses, there was some lack of political will to embrace the training, as there was a view that although there was the potential to improve health outcomes for the residents, the manager did not feel there were sufficient resources to implement the required training. (R4)

Commercial organisations were reported as unwilling to release staff for training unless the value of that training was felt within the organisation. Valuable initiatives by the voluntary sector to train social care staff, but which provided benefits in the healthcare sector, fell between sectors and were potentially unviable without direct funding.

The voluntary sector is happy to participate but there is no spare capacity within it unless there is a financial package that can go with it. (R35)

There was concern that privately funded organisations were not subject to the same standards and mandates as the publicly funded bodies, and were failing to invest in training.
Because it is not mandated, organisations do not have to engage with or release staff for education. (R2)

Restructuring within the NHS has created a set of semiautonomous institutions and organisations with different and sometimes competing priorities. ${ }^{21}$ Some participants described difficulty aligning project aims to multiple organisational goals.

There were tensions between the two boroughs in relation to approach \& resourcing. There was also a tension between commissioner expectations and practice/federation expectations which have impacted on the programmes sustainability. (R16)

So, this intervention has a good return on investment, for every $£ 1$ you spend you get a return of $£ 5.20$. And they'll say, I'm the one making the investment, but he's the one making the return here. I've got a budget; he's got another budget. We might both be in the health system, but I'm not going to spend my money if he's the one getting the return. (FI2)

\section{Workplace cultures and priorities}

Some projects reported finding non-healthcare workers receptive to health-related training; however, some failed or struggling projects found this a challenge.

Medicines delivery teams unwilling to take on additional role. (R61)

There were concerns raised by care home managers that the initiative would cause undue responsibility on individuals to make clinical decisions. (R16)

Participants described differences between academic and workplace learning cultures, and variable receptiveness of front-line clinical staff to change. Some described resistance to outsiders telling healthcare workers how to improve. This may reflect the inverse of high-value projects, which were found to engage in participatory practices, engaging patients, front-line staff and communities in codesigning their innovation.

It has been difficult to embed these products due to structural issues within the staff teams. (Nursing) It was clearly not seen as a priority. (R20)

I think the main insight I would have is that when working with mental health nursing teams the researcher and research team needs to be fully integrated into team(s) and seen as part of the culture. Being an outsider does not seem to work as day-to-day practice seems to regulate research. (R20)

Participants also described tensions between management priorities and the priorities of those working directly with patients.

No interest on part of management. I don't think they have even read it. (R57) 
The initiative was welcomed at service level, however there was little interest at senior management level. (R52)

There is such a dislocation between commissioning and what is happening on the ground. (FI2)

Lack of support beyond the start-up phase

Participants noted ongoing privileging of new innovation over sustaining or scaling up innovations that have already demonstrated their value. For example, clinical academics do not gain publications for ongoing maintenance of innovative practice:

'Research remit probably wouldn't cover [further dissemination] unless there was a good likelihood of REFability' ['REF' refers to the Research Excellence Framework, a scoring system used to fund the university sector]. (R1)

Participants described innovation funding streams, but articulated difficulty securing funding beyond the start-up phase.

The project was resourced sufficiently for the pilot. However, once the pilot finished so did the project. (R5)

The education faculty and funding is driven towards innovation and not sustainability-this de-incentives individuals from continuing with existing projects. (R8)

Burn-out, turnover and lack of protected time

Participants described projects that were limited by staff burn-out, turnover and a lack of protected time.

My commitment to the project was there however the resources I had to continue with project were limited due to competing pressures on my time. (R12)

The programme required more administrative support than anticipated \& this ended up being an ask over \& above someone's day job for a prolonged period of time. (R16)

The most important person was our pharmacist who moved from the pharmacy a few months after we started! (R61)

Risk as integral to innovation

Finally, it is worth noting that participants felt that risk was a necessary ingredient of healthcare innovation. Innovations that fail to demonstrate value should be supported in folding without hesitation, and lessons shared.

The project demonstrated that this initiative was not a model that would work in the hospital environment hence could not be embedded. (R30)

\section{Significance of factors to value creation and expansion}

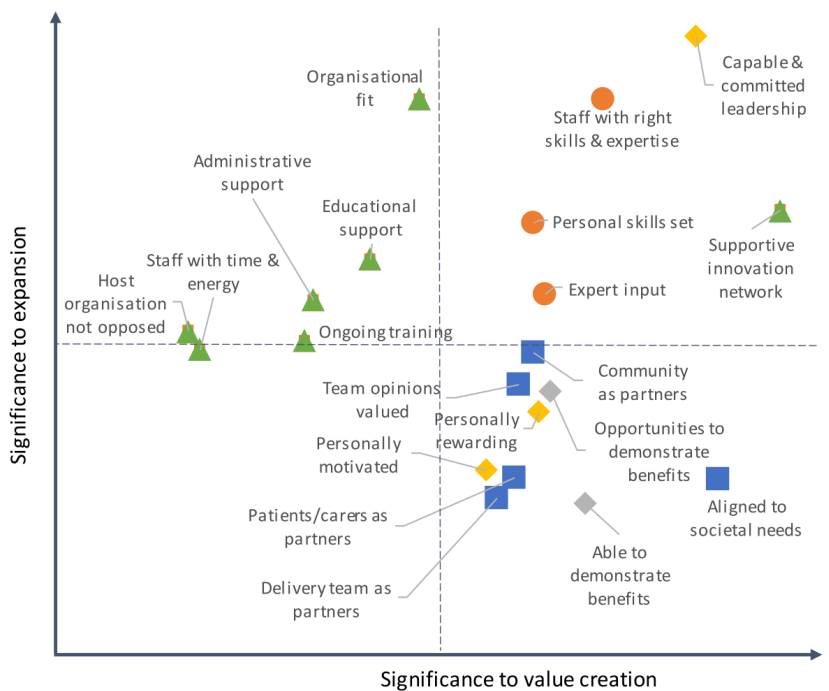

\section{Significance to value creation and expansion of higher value projects}

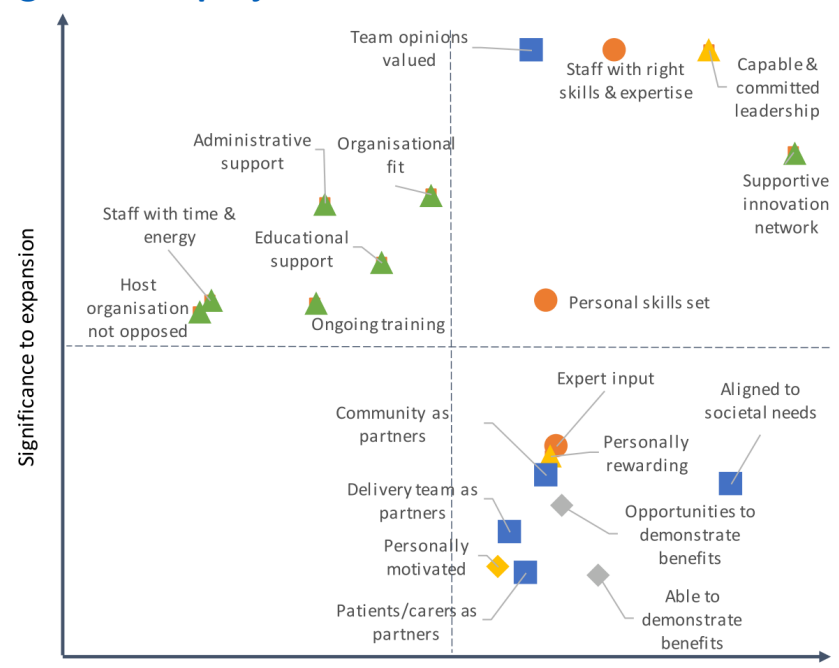

Significance to value creation

Critical success factors plotted according to their significance to success

- Natural logarithmic axes: factors above and to the right of the dotted line have significance $>=0.05$

- Expansion axis: significance to whether a project becomes embedded or spread

- Value creation axis: significance to clinical value "did it work for the intended beneficiaries"

Key

$=$ skills \& expertise

= participation

= evaluation

$\Delta=$ resourcing \& support

= leadership skills \& motivation

Figure 4 Critical success factors plotted according to their salience to success. Critical success factors plotted according to their significance to success on a natural logarithmic scale so that factors above and to the right are probably significant $(p \leq 0.05)$. The expansion axis indicates significance to whether a project is scaled up or down beyond the original pilot. The value creation axis indicates significance as to whether it creates more or less than its intended value for beneficiaries. 


\section{Nested Hierarchy of Needs for Success in Health Service Innovation}

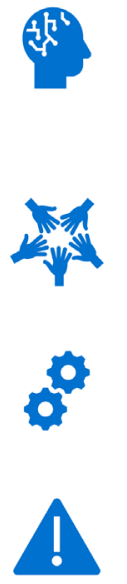

Core success factors are important to whether an innovation creates value, and to whether it embeds or spreads: - Leadership skills, expertise and capability

- Sufficient staff with the right skills and expertise

Expert input and a supportive collaborative network of innovators

Value creation factors are specific to whether an innovation creates value for its intended beneficiaries:

- Involvement of patients, public, practitioners and communities; alignment to societal needs

- Motivated leadership, opportunities to showcase success

Expansion factors are specific to whether a valuable innovation embeds or spreads:

- Organisational fit and support

- Access to administrative and educational support

Staff with time and capacity

Additional limiting factors were described at the boundaries and intersections between organisations, professions, sectors and cultures; lack of structural support beyond the start-up phase; staff burnout and turnover

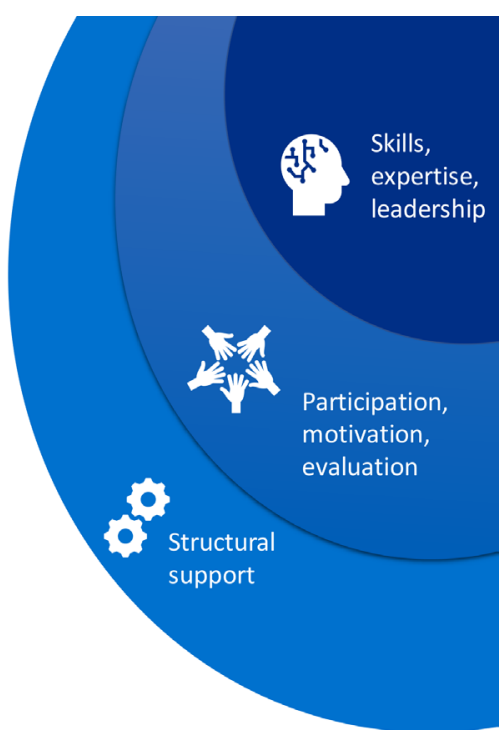

Figure 5 Nested hierarchy of success factors and limiting factors for health service innovation. Factors that may be significant to both value generation for the intended beneficiaries and to whether the innovation is scaled up beyond the original pilot are labelled as core needs. Factors that may be significant specifically to value generation are the next priority (middle layer) as innovations that do not generate value will not become embedded or spread. Finally, factors that may primarily be significant to expansion are presented in the outermost layer. Additional limiting factors were identified through an inductive analysis of qualitative responses from projects that had scaled down or failed to produce their intended value.

\section{Final framework}

We created two $2 \times 2$ matrices containing all the significant success factors across each dimension of success, shown in figure 4. The matrix on the right excluded low-value projects in the calculation of factors significant to expansion and served to support the inclusion of some marginal factors in the final model as they became more significant despite lower power.

Figure 4 shows clearly congruent clusters of factors in each quadrant, indicating that some types of factors may be more important to expansion, while others are more important to value creation. These clusters relate to skills and expertise, leadership and motivation, organisational fit and structural support, societal alignment and participation, and evaluation.

As outlined in table 1, there are questions as to whether evaluation and motivation are dependent rather than independent variables: does finding working on a project personally rewarding drive success or vice versa, and does a positive evaluation drive success or vice versa? Triangulation with qualitative comments (in table 2) suggests that evaluation and motivation may drive success, so they have been tentatively included in our final model.

Themes that were predominantly related to value creation (participation, motivation and evaluation) were labelled value creation factors. Themes that were predominantly significant to expansion (organisational fit and structural support) were labelled expansion factors. Themes that were significant to both axes (expertise, leadership and a supportive network) were labelled core success factors. We arranged success factors into a nested hierarchy, as innovations that do not generate value are unlikely to be scaled up. Our final model in figure 5 also lists potential limiting factors identified through our inductive qualitative analysis.

\section{DISCUSSION}

This analysis of 56 health service innovation projects has enabled us to propose a model for understanding success in health service innovation that has two discrete axes: one relating to whether or not the innovation created value for its intended beneficiaries; the other relating to whether or not it was scaled up beyond the original pilot. Comparing projects across these dimensions of success has enabled us to hypothesise that:

- The core drivers of success are leadership and collaborative expertise (leadership skills and commitment, expert input, sufficient staff with the right skills and expertise, and a supportive collaborative network).

- The drivers of value creation for the intended beneficiaries are participation, motivation and evaluation (involvement of patients, public, practitioners and communities, alignment to societal needs, internal motivation, finding the project work rewarding, ability to demonstrate benefits and having opportunities to share impacts).

- The drivers of sustainability and scale-up are organisation fit and structural support (organisational fit and alignment, administrative and educational support, staff with time and energy).

Additional limiting factors included difficulties at the boundaries and intersections between organisations, professions, sectors and cultures; a lack of structural support beyond the start-up phase; and staff burn-out and turnover. 
Within healthcare services, the issue of diffusion and sustainability of innovation has received widespread academic attention pioneered by Greenhalgh et $a t^{22}$ who drew on Rogers' seminal text on diffusion of innovations. ${ }^{23}$ There have been many subsequent notable academic contributions. ${ }^{24-28}$ Nilsen proposed an overarching framework of healthcare implementation theories according to the aim of the theory. ${ }^{29}$ Theories such as those about innovation sustainability, which include the diffusion of innovation theory, were categorised as 'determinant frameworks', as they posit general types of factors that can influence the success of an innovation. We believe that our findings contribute through empirical evidence to theoretical development at this level, and thus may have wider implications than programme-level data would normally allow. According to Nilsen, such theories have typically been analysed and formulated across individual studies, at the level of meta-analysis or review $^{29}$ and may therefore be one or more steps removed from the underlying data. This study is different in that we have developed mid-range theory that is empirically grounded in programme-level data, and there is a clear line between our data and the generated theory.

Conceptions of innovation success tend to focus on sustainability $^{30}$ and scale-up. ${ }^{24}$ We suggest that both are contingent on the ability of an innovation to provide value to its intended beneficiaries in the first place. There are few theories grounded in empirical data that explain this dimension of success. Our findings highlight the importance of patient, public and practitioner involvement, alongside the core success factors of leadership and collaborative expertise. We suggest that these are fundamental preceding factors to either sustainability or scale-up.

This 'value for intended beneficiaries' dimension of success also allows us to conceptualise a valuable innovation that is not growing or expanding. This, we argue, is important: healthcare innovations may have parameters within which growth and expansion are constrained, perhaps because their aims have been achieved, or because the context changes. An innovation that has met its aims but has not expanded beyond its natural boundary should be properly positioned as such.

Our ability to research a set of potentially valuable projects that were scaled down or stopped, many of which never reach the literature, may have afforded novel insights. Fixsen et al suggest that sustainability can only be asserted when the funding to support implementation is withdrawn. ${ }^{31}$ Wiltsey Stirman et als systematic review suggests sustainability can be asserted after a period of 2 years. ${ }^{32}$ Our findings suggest that continued structural support, particularly organisational, administrative and educational support, may be critical to a project's sustainability and scalability, and that their withdrawal may destroy potentially valuable innovations.

Finally, our findings further validate the work of Dopson et $a l^{33}$ whose qualitative exploration of a similar set of health service innovations highlighted the importance of context and process over content: it is not so much what you are trying to achieve, it is how you do it and the organisational and interpersonal contexts that you work within that matter.

A limitation of this research is its highly contextual nature. Our results may not be generalisable to all contexts; however, repeating these methods may produce locally relevant results. The ANOVA depends on the universe of potential factors having been correctly identified and a large enough number of innovations to produce statistical significance. The research could be improved by more extensive validation of factors, patient and public involvement, further testing the directionality of tentative factors, a greater geographical spread and a greater number of projects to allow for finer grading across the expansion axis.

\section{CONCLUSIONS}

Our findings suggest that organisations and policy makers wishing to support service-level innovation in similar healthcare contexts address the factors identified through this research as critical to success.

Such strategies might include:

- Supporting innovators with the right skills and expertise, including leadership skills, implementation support and evaluation expertise.

- Innovation networks to provide opportunities to showcase success and provide a peer community of expertise and support.

- Emphasising participatory practices and collaborative approaches, so that innovations are more likely to align to societal and organisation goals and generate value for patients, communities and practitioners.

- Providing administrative and educational support during the scale-up phase, and ensuring that this support is maintained or handed over rather than withdrawn to schedule.

- Recognising and enhancing the internal motivation and drive of innovators as well as more goal-oriented motivations such as career needs.

At a structural level, the boundaries between organisations, professions and the health and social care sectors may need to be addressed as potential barriers to successful innovation.

More research is needed to confirm whether addressing these factors prospectively enhances the success of future innovations.

Twitter Kathleen Leedham-Green @doctorkayleigh

Acknowledgements We would like to thank Josh Brewster from the Health Innovation Network and Sian Kitchen from Health Education England for their commitment to this project, and Professor Sue Smith from the Medical Education Research Unit of Imperial College for ongoing support and advice.

Contributors $\mathrm{KL}-\mathrm{G}$ and GBR contributed to the conception and design of the work and to the acquisition of data. KL-G, GBR and AK collaborated on the data analysis and interpretation. KL-G and AK drafted the work, all authors revised it critically for important intellectual content. All authors have approved the final version and agree 
to be accountable for all aspects of the work and to resolve questions relating to accuracy or integrity.

Funding This work was funded by Health Education England (grant number XXMLIVESEY).

Disclaimer Gabriel Reedy is affiliated to the National Institute for Health Research Health Protection Research Unit (NIHR HPRU) in Emergency Preparedness and Response at King's College London in partnership with Public Health England (PHE), in collaboration with the University of East Anglia and Newcastle University. The views expressed are those of the author(s) and not necessarily those of the NHS, the NIHR, the Department of Health or Public Health England. These funders had no input in the writing of and the decision to submit this article.

Competing interests None declared.

Patient consent for publication Not required.

Ethics approval Ethical approval was granted on 26 March 2019 by the Research Ethics Committee of King's College London (LRS-18/19-10432).

Provenance and peer review Not commissioned; externally peer reviewed.

Data availability statement Data are available upon reasonable request. Due to the highly individual nature of healthcare innovations and the limited geographic area of this study, we are unable to provide our raw data. We undertake to provide a redacted data set upon reasonable request.

Supplemental material This content has been supplied by the author(s). It has not been vetted by BMJ Publishing Group Limited (BMJ) and may not have been peer-reviewed. Any opinions or recommendations discussed are solely those of the author(s) and are not endorsed by BMJ. BMJ disclaims all liability and responsibility arising from any reliance placed on the content. Where the content includes any translated material, BMJ does not warrant the accuracy and reliability of the translations (including but not limited to local regulations, clinical guidelines, terminology, drug names and drug dosages), and is not responsible for any error and/or omissions arising from translation and adaptation or otherwise.

Open access This is an open access article distributed in accordance with the Creative Commons Attribution Non Commercial (CC BY-NC 4.0) license, which permits others to distribute, remix, adapt, build upon this work non-commercially, and license their derivative works on different terms, provided the original work is properly cited, appropriate credit is given, any changes made indicated, and the use is non-commercial. See: http://creativecommons.org/licenses/by-nc/4.0/.

\section{ORCID iDs}

Kathleen Leedham-Green http://orcid.org/0000-0002-5010-3257

Alec Knight http://orcid.org/0000-0002-2937-436X

Gabriel B Reedy http://orcid.org/0000-0002-1839-1949

\section{REFERENCES}

1 Global Burden of Disease Health Financing Collaborator Network. Past, present, and future of global health financing: a review of development assistance, government, out-of-pocket, and other private spending on health for 195 countries, 1995-2050. Lancet 2019;393:2233-60.

2 Crisp N. What would a sustainable health and care system look like? BMJ 2017;358:j3895.

3 Nolte E. How do we ensure that innovation in health service delivery and organization is implemented sustained and spread. World Health Organization, 2018.

4 Bornmann L, Haunschild R. Societal Impact Measurement of Research Papers. In: Glänzel W, Moed HF, Schmoch U, eds. Springer Handbook of science and technology indicators. Cham: Springer International Publishing, 2019: 609-32.

5 Pury EF, Davide N, Jean L. Nhs top managers, knowledge exchange and leadership: the early development of academic health science networks - a mixed-methods study, 2017.

6 Davidoff F, Dixon-Woods M, Leviton L, et al. Demystifying theory and its use in improvement. BMJ Qual Saf 2015;24:228-38.

7 McCulloch P, Altman DG, Campbell WB, et al. No surgical innovation without evaluation: the ideal recommendations. Lancet 2009;374:1105-12.
8 Bogna F, Raineri A, Dell G. Critical realism and constructivism: merging research paradigms for a deeper qualitative study. $Q R O M$ 2020;15:461-84.

9 Varpio L, Paradis E, Uijtdehaage S, et al. The distinctions between theory, theoretical framework, and conceptual framework. Acad Med 2020;95:989-94.

10 Creswell JW, Plano Clark VL, Gutmann ML. Advanced mixed methods research designs. In: Handbook of mixed methods in social and behavioral research. , 2003: 209, 240.

11 Saunders B, Sim J, Kingstone T, et al. Saturation in qualitative research: exploring its conceptualization and operationalization. Qual Quant 2018;52:1893-907.

12 Lennox L, Maher L, Reed J. Navigating the sustainability landscape: a systematic review of sustainability approaches in healthcare. Implement Sci 2018;13:27.

13 Creswell JW, Hirose M. Mixed methods and survey research in family medicine and community health. Fam Med Community Health 2019;7:e000086.

14 Charmaz K. Constructing grounded theory: a practical guide through qualitative analysis. London: Sage, 2006.

15 Jebb AT, Parrigon S, Woo SE. Exploratory data analysis as a Foundation of inductive research. Hum Resour Manag Rev 2017;27:265-76.

16 Hecke TV. Power study of ANOVA versus Kruskal-Wallis test. J Stat Manag Syst 2012;15:241-7.

17 Poots AJ, Reed JE, Woodcock T, et al. How to attribute causality in quality improvement: lessons from epidemiology. BMJ Qual Saf 2017;26:933-7.

18 Braun V, Clarke V. Thematic analysis. In: APA handbook of research methods in psychology, vol 2: research designs: quantitative, qualitative, neuropsychological, and biological. Washington, DC, US: American Psychological Association, 2012: 57--71.

19 The Health Innovation Network. Health innovation network - our projects, 2021. Available: https://healthinnovationnetwork.com/ourprojects/ [Accessed 26 Mar 2021].

20 The King's Fund. Key facts and figures about adult social care, 2019. Available: https://www.kingsfund.org.uk/audio-video/key-factsfigures-adult-social-care [Accessed 12 Dec 2020].

21 Gadsby EW, Peckham S, Coleman A, et al. Commissioning for health improvement following the 2012 health and social care reforms in England: what has changed? BMC Public Health 2017;17:211-11.

22 Greenhalgh T, Robert G, Bate P. Diffusion of innovations in health service organisations: a systematic literature review. Wiley, 2008.

23 Rogers EM. Diffusion of innovations. New York: Free Press of Glencoe, 1962.

24 Greenhalgh T, Robert G, Macfarlane F, et al. Diffusion of innovations in service organizations: systematic review and recommendations. Milbank Q 2004;82:581-629.

25 Kitson AL, Rycroft-Malone J, Harvey G, et al. Evaluating the successful implementation of evidence into practice using the PARiHS framework: theoretical and practical challenges. Implement Sci 2008;3:1.

26 Damschroder LJ, Aron DC, Keith RE, et al. Fostering implementation of health services research findings into practice: a consolidated framework for advancing implementation science. Implement Sci 2009;4:50.

27 Aarons GA, Hurlburt M, Horwitz SM. Advancing a conceptual model of evidence-based practice implementation in public service sectors. Adm Policy Ment Health 2011;38:4-23.

28 Nolte E. How do we ensure that innovation in health service delivery and organization is implemented sustained and spread? World Health Organization, 2018.

29 Nilsen P. Making sense of implementation theories, models and frameworks. Implement Sci 2015;10:53.

30 Moore JE, Mascarenhas A, Bain J, et al. Developing a comprehensive definition of sustainability. Implement Sci 2017;12:110.

31 Fixsen DL, Naoom SF, Blase KA. Implementation research: a synthesis of the literature, 2005.

32 Wiltsey Stirman S, Kimberly J, Cook N, et al. The sustainability of new programs and innovations: a review of the empirical literature and recommendations for future research. Implement Sci 2012;7:17.

33 Dopson S, Fitzgerald L, Ferlie E. Understanding change and innovation in healthcare settings: Reconceptualizing the active role of context. J Chang Manag 2008;8:213-31. 